\title{
Axonal Signals Regulate Expression of Glia Maturation Factor-Beta in Schwann Cells: An Immunohistochemical Study of Injured Sciatic Nerves and Cultured Schwann Cells
}

\author{
E. Peter Bosch, Weixiong Zhong, and Ramon Lim \\ Department of Neurology, Division of Neurochemistry and Neurobiology, The University of lowa College of Medicine, and \\ Veterans Administration Medical Center, lowa City, lowa 52242
}

\begin{abstract}
Glia maturation factor-beta (GMF-beta) is a $17 \mathrm{kDa}$ protein purified and sequenced from bovine brains. Using the monoclonal antibody G2-09 directed against GMF-beta, we previously demonstrated endogenous GMF-beta in astroblasts, Schwann cells, and their tumors in culture. In the present study, we have used indirect immunofluorescence microscopy with G2-09 to examine the effects of transection, crush, and regeneration of sciatic nerve on the expression of GMF. beta in Schwann cells in situ and to study the time course of GMF-beta induction in Schwann cells in vitro. For comparison, a parallel study was carried out with monoclonal antibodies directed against nerve growth factor (NGF) receptor. We found that (1) neither GMF-beta nor NGF receptor was detectable in intact sciatic nerves, (2) all Schwann cells of the distal segment of the transected nerve expressed GMF-beta as early as $3 \mathbf{d}$ after axotomy that persisted up to 3 weeks, (3) axonal regeneration repressed the Schwann cell expression of GMF-beta, (4) isolated Schwann cells derived from rat sciatic and adult human sural nerves developed intracellular GMF-beta in culture following an initial lag period, and (5) the induction of Schwann cell NGF receptor coincided temporally with that of GMF-beta in the transected nerve and in culture. These results show that the expression of GMF-beta in Schwann cells, as is the case with the NGF receptor, is induced by the loss of the normal axon-Schwann cell contact. We propose that the induction of GMF-beta, as well as NGF receptor, in Schwann cells after nerve injury plays a role in axonal regeneration.
\end{abstract}

Glia maturation factor (GMF) was detected as an acidic protein that stimulated the proliferation and phenotypic expression of astroblasts (Lim et al., 1972, 1973, 1976, 1977a, 1977b; Lim and Mitsunobu, 1974) and Schwann cells (Bosch et al., 1984) in culture. The protein was isolated from bovine brains, and monoclonal antibodies against GMF were obtained that adsorbed the biological activity of GMF (Lim et al., 1985a). Recently, a further refinement in the purification procedure led to

\footnotetext{
Received Nov. 8, 1988; revised Mar. 1, 1989; accepted Mar. 23, 1989.

We wish to thank Dr. Nicholas Pantazis for help in the procurement of the monoclonal antibodies 192-IgG and NGFR, and Jean Hulme and Louis Facto for manuscript preparation. This work was supported by VA Merit Review Award, NSF grant BNS-8607283, and Diabetes-Endocrinology Research Center grant DK-25295.

Correspondence should be addressed to E. Peter Bosch, M.D., F.A.C.P., Department of Neurology, The University of Iowa Hospitals \& Clinics, Iowa City, IA 52242 .

Copyright (C) 1989 Society for Neuroscience $0270-6474 / 89 / 103690-09 \$ 02.00 / 0$
}

the isolation of a pure protein recognized by the monoclonal antibody G2-09, designated GMF-beta (Lim and Miller, 1988). GMF-beta is a $17 \mathrm{kDa}$ protein with an isoelectric point of $\mathrm{pH}$ 4.9. The amino acid composition shows an estimated length of 140 residues, of which over two thirds have been successfully sequenced (Lim and Miller, 1988; Lim et al., 1989). A search through the Protein Identification Resource (formerly National Biomedical Research Foundation) database showed no significant homology with any other proteins, including other growth factors isolated from the brain, such as acidic and basic fibroblast growth factors (aFGF and bFGF).

The monoclonal antibody $\mathrm{G} 2-09$, an $\mathrm{IgG}_{2 \mathrm{~b}}$ that binds specifically to GMF-beta (Lim and Miller, 1988; Lim et al., 1989), was used to localize GMF-beta immunoreactivity in cell cultures and to study its distribution in situ in developing and adult rats. In general, endogenous GMF-beta was restricted to central and peripheral glia. Among the various cell types tested in vitro, only astrocytes, Schwann cells, and their tumors contained intracellular GMF-beta (Lim et al., 1987a, 1988a). In the adult rat, with the questionable exception of the heart, GMF-beta was found exclusively in the CNS, of which the cerebellum exhibited a higher specific activity than other brain regions (Lim et al., 1987b). Immunocytochemical staining of the brain and spinal cord sections localized GMF-beta to astrocytes and Bergmann glia (Lim et al., 1987b). Some age-dependent decline in GMFbeta immunoreactivity was found, being highest in fetal brains, although substantial levels persisted in adult animals (Lim et al., 1987b). A phylogenetic comparison revealed the presence of GMF-beta in the brain of all vertebrates studied, from fish to primates (Lim et al., 1987b).

While working on the in situ distribution of endogenous GMFbeta, we noticed that the protein was not detectable in intact peripheral nerves (Lim et al., 1988b), although high levels were found in cultured Schwann cells (Lim et al., 1988a). This posed an intriguing question. Might GMF-beta expression in the peripheral nervous system be modulated by axonal signals? In the present work, we addressed this question by studying the effects of ncrve transcction, crush, and regeneration on the expression of GMF-beta in Schwann cells in situ and by examining the time course of GMF-beta expression in neonatal and adult Schwann cells in vitro. Because other investigators have reported that NGF receptors are expressed by Schwann cells only in culture or following nerve injury (Taniuchi et al., 1986; Yasuda et al., 1987), a parallel study was carried out with monoclonal antibodies directed against rat and human NGF receptors. Our results indicate that the expression of GMF-beta in Schwann 
cells, as is the case with the NGF receptor, is induced by the loss of normal axon-Schwann cell contact.

\section{Materials and Methods}

Transection or crush of sciatic nerve. Adult female Sprague-Dawley (SD) rats $(280-320 \mathrm{gm}$ body weight) were anesthetized with a $5 \%$ halothane$100 \%$ oxygen mixture. The sciatic nerve was 1ransected between 2 silk ligatures placed $3 \mathrm{~mm}$ apart around the nerve trunk just below the sciatic notch. The proximal nerve stump was sewn into the adjacent muscle to prevent axonal regeneration into the distal stump. The contralateral sciatic nerve, which was sham operated, i.e., exposed without injury, served as control. In other experiments, the exposed sciatic nerve was crushed for $30 \mathrm{sec}$ using watchmaker forceps below the sciatic notch in order to allow axonal regeneration into the distal stump. At specific time periods, ranging from $1 \mathrm{~d}$ to 2 months after injury, the animals were killed by decapitation, and both sciatic nerves were removed for immunostaining of teased fibers and frozen sections. Teased fibers from the proximal and distal nerve stumps and contralateral noninjured sciatic nerves were immediately prepared in a small pool of PBS on microscope slides (Jessen and Mirsky, 1984). Samples were allowed to air dry and then were frozen at $-80^{\circ} \mathrm{C}$ before immunostaining. For transverse sections, distal nerve stumps and contralateral control sciatic nerve samples were mounted on cork discs using OCT-II compound before being frozen in isopentane cooled in liquid nitrogen.

Schwann cell cultures. Primary Schwann cell cultures were established from sciatic nerves of 2-4-d-old SD rats according to our standard procedure (Assouline et al., 1983). The cells were grown on poly-Llysine $(0.1 \%$; Sigma)-coated glass coverslips in F12 nutrient mixed with Dulbecco's modified Eagle's medium (F12/DMEM, 1:1, vol/vol) containing $10 \%$ fetal calf serum, $100 \mathrm{U} / \mathrm{ml}$ penicillin, and $100 \mu \mathrm{g} / \mathrm{ml}$ streptomycin. Human Schwann cells obtained from normal sural nerve of a young adult undergoing leg amputation for osteosarcoma were dissociated after incubation overnight in RPMI 1640 medium containing an enzyme mixture consisting of $1.25 \mathrm{U} / \mathrm{ml}$ dispase (Behringer), $0.05 \%$ collagenase, and $0.1 \%$ hyaluronidase (Sigma) (Pleasure et al., 1986). The cells seeded on poly-L-lysine-coated glass coverslips were maintained in RPMI 1640 medium supplemented with $15 \%$ fetal calf serum. After $2 \mathrm{~d}$ in culture, the cells were treated with $10^{-3} \mathrm{M}$ cytosine arabinoside for $2 \mathrm{~d}$ to reduce fibroblast contamination.

Sources of antibodies. The mouse monoclonal antibody G2-09, an $\mathrm{IgG}_{2 \mathrm{~b}}$ raised against bovine GMF-beta, was prepared as previously described (Lim et al., 1985a). A stock solution after a 10-fold concentration (by Amicon filtration) of the hybridoma-conditioned medium was used at a dilution of 1:20 for cell cultures and teased fiber preparations, or at 1:10 for tissue sections. The mouse anti-rat NGF receptor monoclonal antibody 192-IgG, produced by Chandler et al. (1984) and provided by Dr. E.M. Johnson, Washington University School of Medicine, was used at $1.3 \mu \mathrm{g} / \mathrm{ml}$. The monoclonal antibody against human NGF receptor $\mathrm{NGFR}_{s}$, produced by Marano et al. (1987) and provided by Dr. M. Bothwell, University of Washington, Seattle, was used at $2.5 \mu \mathrm{g} / \mathrm{ml}$. FITC-conjugated goat antimouse IgG purchased from Sigma was used at a dilution of 1:100.

Immunofluorescence. For staining with the G2-09 monoclonal antibody cell cultures, teased fiber preparations and $10 \mu \mathrm{m}$ cross-sections of sciatic nerve were washed in PBS, fixed with $3 \%$ paraformaldehyde in PBS for $30 \mathrm{~min}$ at $4^{\circ} \mathrm{C}$, and subsequently permeabilized for $10 \mathrm{~min}$ at $-20^{\circ} \mathrm{C}$ with acetone. For NGF receptor staining with 192-IgG or $\mathrm{NGFR}_{5}$, permeabilization with acetone was omitted for teased fiber preparations and nerve sections. For cell cultures, the staining procedure for NGF receptor was carried out on unfixed, unpermeabilized cells. After preincubation with PBS containing 3\% normal goat serum, the coverslips or microscope slides were overlaid with G2-09 against GMFbeta or $192 \mathrm{IgG}$ against rat NGF reccptor or $\mathrm{NGFR}_{5}$ against human NGF receptor for $1 \mathrm{hr}$ at room temperature, rinsed with PBS, and then overlaid with FITC conjugated goat antimouse IgG for $1 \mathrm{hr}$. Unfixed cell cultures were postfixed in acid-alcohol at $-20^{\circ} \mathrm{C}$. All rinses and dilutions were conducted in PBS containing 3\% normal goat serum. After washing in PBS, the coverslips were mounted in glycerol/PBS (9: 1) containing $0.1 \%$ (wt/vol) 1,4-diazobicyclo-[2,2,2] octane (Dabco) to suppress fluorochrome fading. All preparations were examined with a Zeiss microscope fitted for epifluorescence with $20 \times$ and $40 \times$ phaseplan-neofluar objectives. Photographs were taken using Kodak Ektachrome 400 film.

\section{Results}

Immunohistochemical localization of GMF-beta after axotomy

Teased fibers of sciatic nerve were immunostained in order to look for GMF-beta expression in Schwann cells of normal myelinated fibers and fibers undergoing Wallerian degeneration. For the first $2 \mathrm{~d}$ after transection, teased fibers of the distal segment appeared normal by phase contrast microscopy. Similarly, immunostaining of these fibers with G2-09 and 192 IgG monoclonal antibodies was negative. At day 3 postinjury, most myelinated fibers showed typical changes of Wallerian degeneration by breaking up into linear rows of myelin ovoids. At the same time, the Schwann cells containing myelin debris began to express GMF-beta immunoreactivity (Fig. 1). The staining was most intense $7 \mathrm{~d}$ after injury and persisted up to 3 weeks, which was the longest time period investigated. The denervated Schwann cell columns or bands of Büngner, which could be identified readily in teased fiber preparations, demonstrated especially intense intracellular staining. Since axotomy induces the expression of NGF receptor in Schwann cells, we also examined teased fibers of the distal nerve segment using $192 \mathrm{IgG}$ as an immunohistochemical marker for the receptor (Taniuchi et al., 1986). At $3 \mathrm{~d}$ posttransection, all fibers were labeled with 192 IgG. This persisted for up to 3 weeks (Fig. 2). In contrast to the G2-09 labeling, immunostaining with $192 \mathrm{IgG}$ was finely speckled, a characteristic feature of cell surface immunofluorescence. There was no detectable immunostaining with either G2-09 or $192 \mathrm{IgG}$ in teased fibers of the proximal nerve stump and sham-operated normal sciatic nerve. Transverse sections of the distal sciatic nerve segment confirmed the expression of GMF-beta in endoneurial Schwann cells 1-3 weeks after transection (Fig. 3). Adjacent sections immunostained with 192-IgG showed an identical staining pattern, indicating that the G2-09 positive endoneurial cells were NGF receptor-positive Schwann cells. The contralateral uninjured sciatic nerve showed no detectable immunostaining.

\section{Immunohistochemical localization of GMF-beta after nerve crush and regeneration}

To determine whether GMF-beta expression could again be repressed in Schwann cells as a result of axonal regeneration, teased fibers of the distal segment were immunostained with G2-09 after proximal sciatic nerve crush. In agreement with the preceding experiment, the myelinated fibers undergoing axonal degeneration showed intense G2-09-positive staining 1 week postcrush injury. Subsequently, the thinly myelinated fibers of the reinnervated distal segment showed no detectable immunostaining 2 months after crush injury (Fig. 4). The lack of GMF-beta expression in the reinnervated nerve segment following crush injury suggests that GMF-beta expression is downregulated in Schwann cells by axonal signals.

\section{GFM-beta expression in cultured Schwann cells}

We have demonstrated previously the expression of GMF-beta in cultured rat Schwann cells by immunodotting, immunoblotting, and immunofluorescence. All Schwann cells that had been maintained in culture for 1 week or longer showed intracellular immunostaining with G2-09. The intracellular localization of GMF-beta was confirmed by the lack of staining unless the cells were initially fixed and permeabilized (Lim et al., 1988a). The current experiments were performed to study the time course 

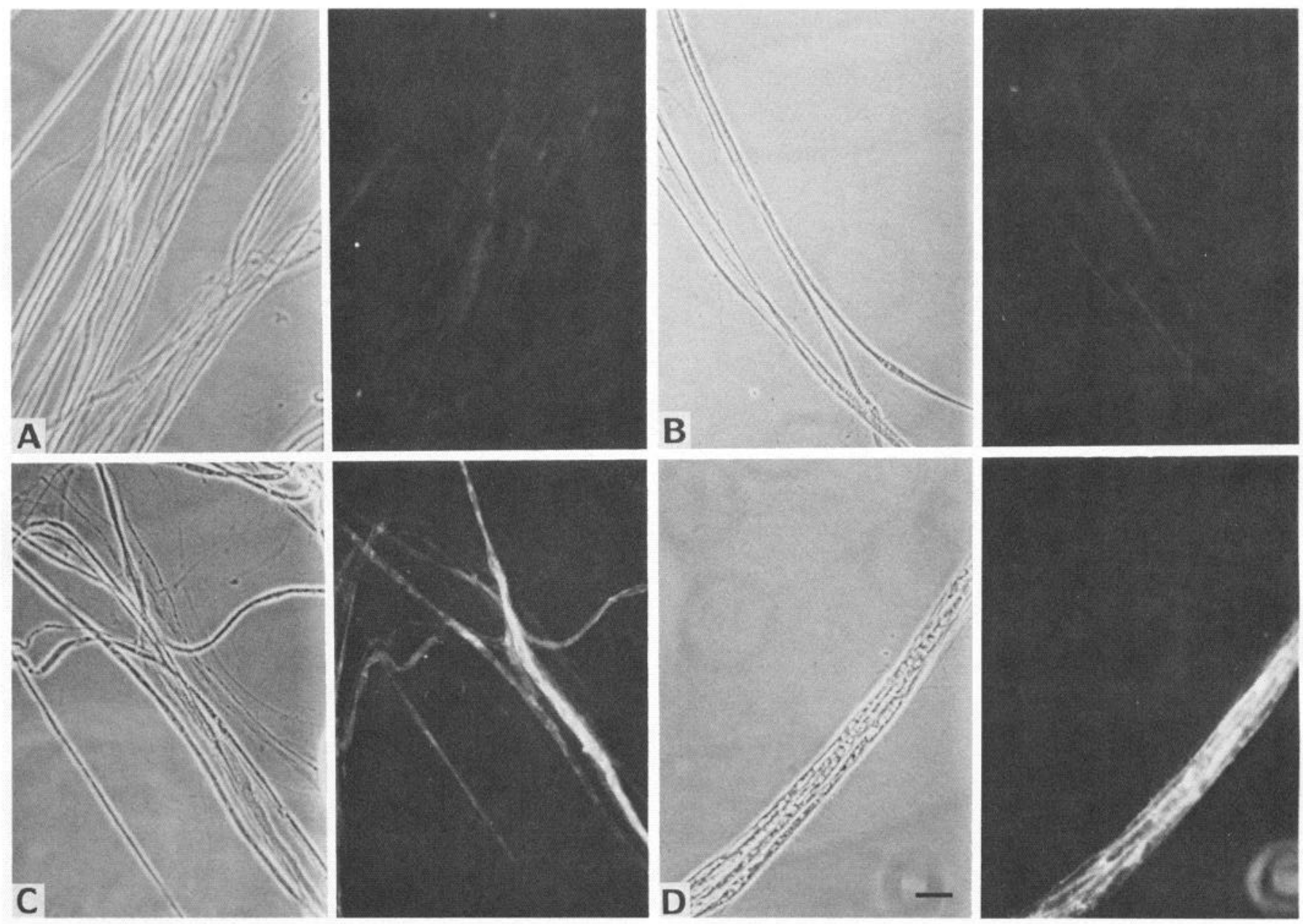

Figure 1. GMF-beta immunoreactivity in teased fiber preparation of sciatic nerve. Phase contrast (left panels) and fluorescein optics (right panels) to visualize GMF-beta. $A$, Control nerve. $B, 1 \mathrm{~d}, C, 3 \mathrm{~d}$, and $D, 7 \mathrm{~d}$ posttransection of sciatic nerve. Note G2-09-positive staining of myelinated fibers undergoing Wallerian degeneration 3 and $7 \mathrm{~d}$ after transection, whereas normal myelinated fibers or fibers $1 \mathrm{~d}$ after injury are unstained. Scale bar, $50 \mu \mathrm{m}$.

of appearance of GMF-beta immunoreactivity and to determine whether Schwann cells derived from adult nerve also maintain the ability to express GMF-beta. Expression of GMF-beta first began to appear in neonatal rat Schwann cells $12 \mathrm{hr}$ in culture but was not detectable immediately after dissociation or after $6 \mathrm{hr}$ in culture. All bipolar spindle-shaped cells of Schwann cell morphology were G2-09 positive at 1 and $7 \mathrm{~d}$ in culture (Fig. 5 ). To verify the purity of our Schwann cell cultures, morphological and immunocytochemical criteria were used. All typical spindle-shaped cells having been maintained for 1 or more $d$ in culture were identified as Schwann cells by their expression of surface NGF receptor (Fig. 5; Zimmerman and Sutter, 1983). Endoneurial fibroblasts were not found to express GMF-beta or NGF receptor. Adult Schwann cells (rat and human) that had been maintained for 3 or more $d$ in culture expressed both GMFbeta immunoreactivity and NGF receptor. All spindle-shaped human Schwann cells derived from sural nerve were positive from GMF-beta immunostaining and confirmed as Schwann cells by surface NGF receptor labeling using the monoclonal antibody $\mathrm{NGFR}_{5}$, which recognizes specifically the human NGF receptor (Fig. 6). The time-dependent appearance of GMF-beta in cultured Schwann cells is in agreement with the results of the in situ nerve transection experiments. Both in culture and after nerve injury, GMF-beta expression in Schwann cells is induced as a consequence of loss of the normal axon-Schwann cell contact.

\section{Discussion}

The cellular localization of a growth factor promises to provide important clues about its biological function. With the development of the monoclonal antibody G2-09 directed against GMF-beta, we previously demonstrated the expression of GMFbeta in astroblasts, Schwann cells, and their tumor cell lines in culture (Lim et al., 1987a, 1988a). In the present study, we have sought to define the conditions under which Schwann cells express GMF-beta immunoreactivity. We have demonstrated that neither myelin-forming nor nonmyelin-forming Schwann cells show detectable G2-09 immunostaining in the intact sciatic nerve of adult animals. After axotomy, produced by either transecting or crushing the sciatic nerve, all Schwann cells of the segments distal to the lesion express GMF-beta, precisely as do dissociated Schwann cells in culture. The time course of GMFbeta expression after nerve transection suggests that Schwann cells respond to axonal degeneration by producing GMF-beta. Immunostaining of teased fibers distal to the injury began revealing positive G2-09 labeling of Schwann cells $3 \mathrm{~d}$ after ax- 

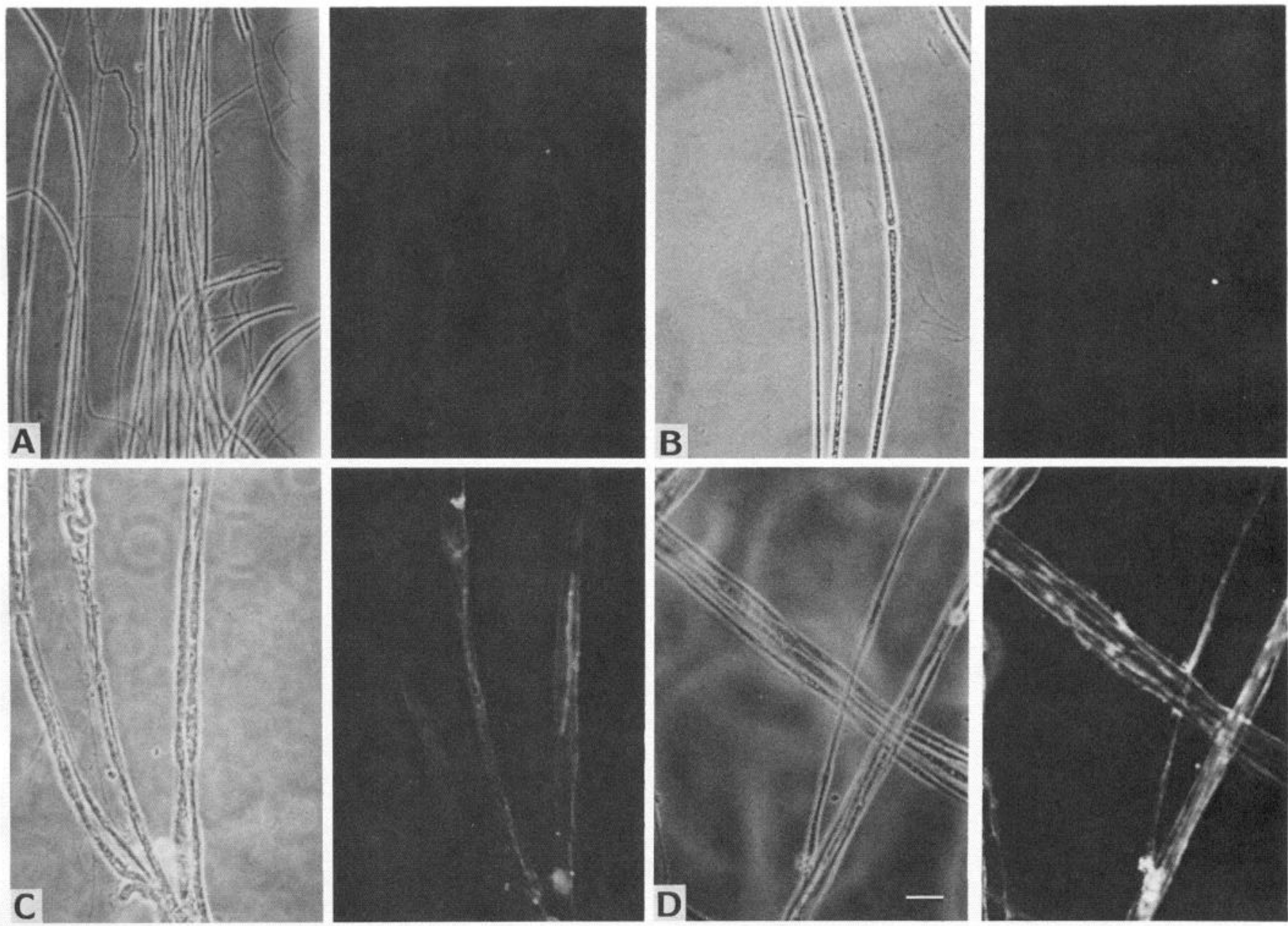

Figure 2. NGF receptor immunoreactivity in teased fiber preparation of sciatic nerve. Phase contrast (left panels) and fluorescein optics (right panels) to visualize NGF receptor. $A$, Control nerve. $B, 1 \mathrm{~d}, C, 4 \mathrm{~d}$, and, $D, 7 \mathrm{~d}$ after nerve transection. The myelinated fibers undergoing Wallerian degeneration are stained for NGF receptor, whereas normal myelinated fibers or fibers $1 \mathrm{~d}$ after injury are unstained. Scale bar, $50 \mu \mathrm{m}$.

otomy, coinciding with Wallerian degeneration of distal fibers, which became most intense $7 \mathrm{~d}$ postinjury and persisted for up to 3 weeks. When we used the monoclonal antibody $192-\operatorname{IgG}$ (which binds specifically to the rat NGF receptor; see below), as positive control in our experiments, we demonstrated that the time course of GMF-beta expression correlated with that of NGF receptor induction in nerve segments distal to axotomy (Taniuchi et al., 1986). That Schwann cells, but neither fibroblasts nor macrophages, contributed to GMF-beta expression is strongly suggested by the fact that single teased fibers undergoing Wallerian degeneration were immunostained and that the uniform G2-09 staining pattern of transverse sections resembled the immunohistochemical localization of NGF receptor in adjacent serial sections.

The effects of axonal regeneration on Schwann cell expression of GMF-beta were studied further by producing crush lesions of sciatic nerve. Nerve crush with fine forceps causes Wallerian degeneration of distal fibers but preserves continuity of the endoneurium and connective tissue compartments of the nerve trunk, which allows subsequent axonal regeneration. Nerve crush was effective in inducing the expression of GMF-beta in distal Schwann cells. After subsequent axonal regeneration, the Schwann cells of regenerating, thinly myelinated fibers showed, similar to intact fibers, no detectable immunostaining with G209. The results indicate that GMF-beta expression in Schwann cells is regulated by axon-Schwann cell signals.

Immunohistochemical examination of Schwann cell cultures provided supplementary confirmation of the in vivo experiments. When Schwann cells were isolated from newborn or adult rat sciatic nerve and placed into tissue culture, they began expressing intracellular GMF-beta within $24 \mathrm{hr}$, again suggesting that removal from axonal contact induces GMF-beta. Since the G2-09 antibody cross-reacts with human tissue, we could also demonstrate immunostaining of human Schwann cell cultures. Concomitantly, Schwann cells developed NGF receptors on their cell surface in a similar time course (Yasuda et al., 1987; Distefano and Johnson, 1988). Co-culture experiments, in which sciatic nerve-derived Schwann cells were added to dorsal root ganglia, have provided a clear picture of the spatial relationship between Schwann cell GMF-beta expression and axonal contact. Preliminary results have shown that Schwann cells in contact with neurites are no longer immunostained with G2-09, in contrast to the positively labeled, solitary Schwann cells at the periphery of the culture (unpublished observations). Thus we conclude that the loss of normal axon-Schwann cell contact induces GMF-beta expression in Schwann cells, whereas reestablish- 

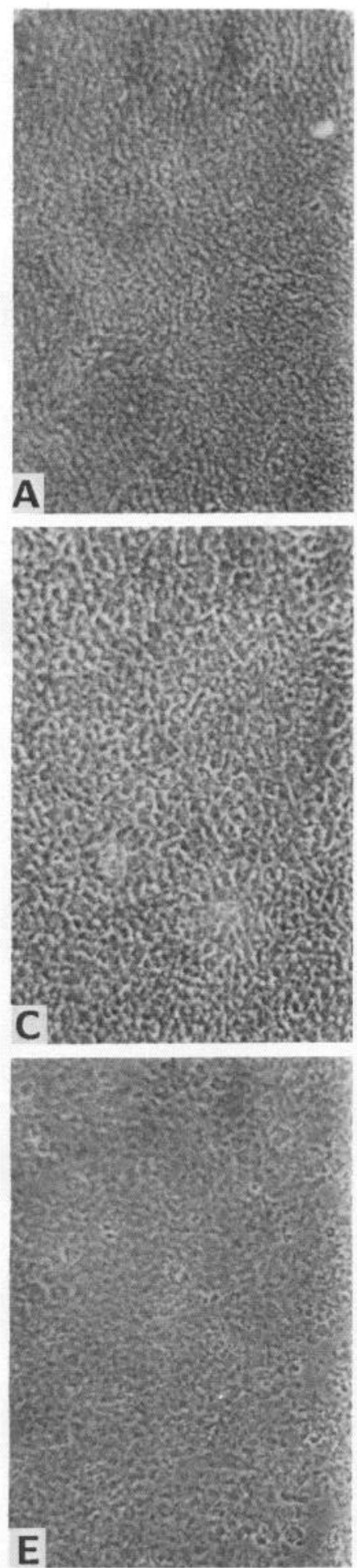
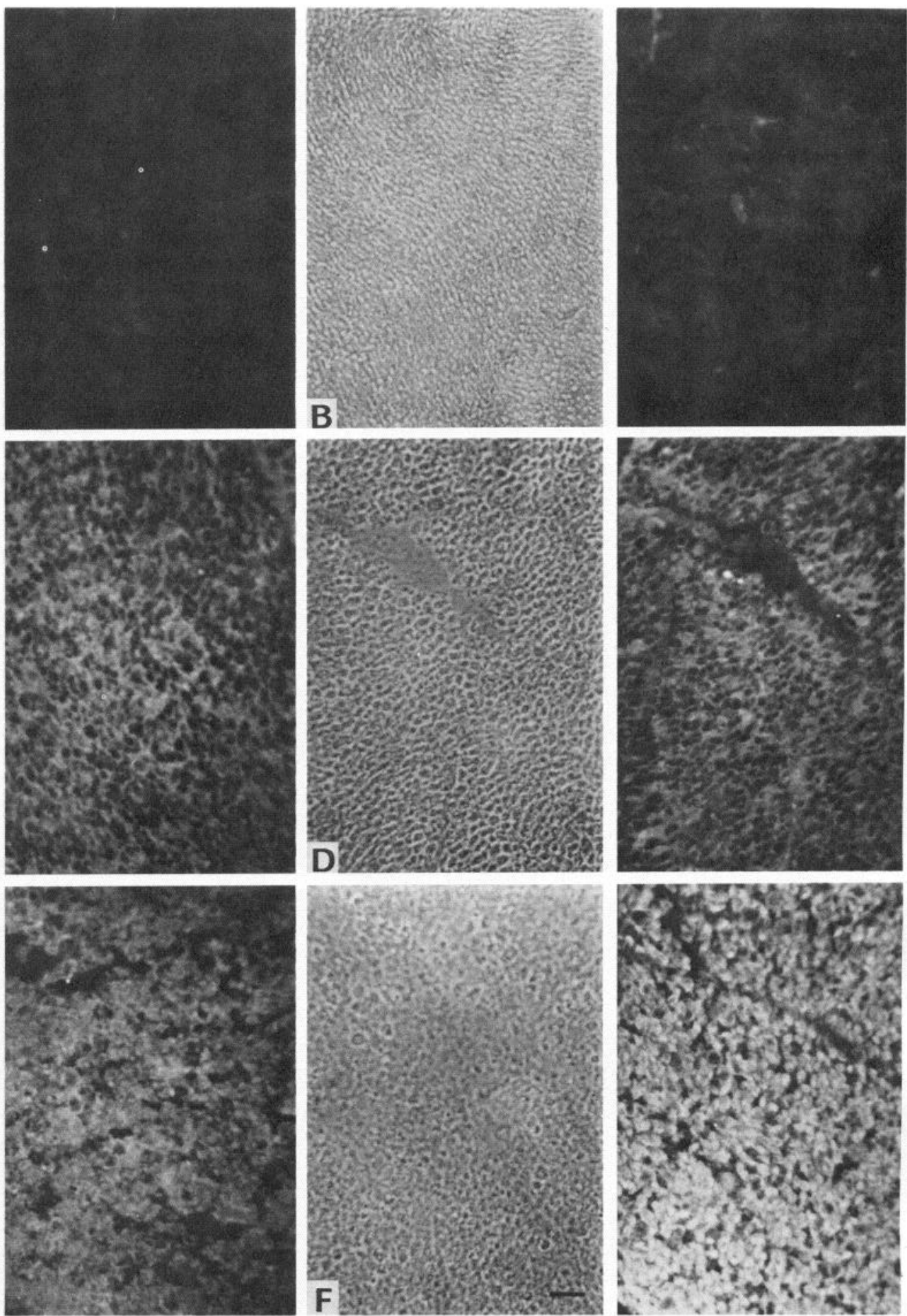

Figure 3. GMF-beta and NGF receptor immunoreactivity in transverse sections of sciatic nerve. Phase contrast (left panels) and fluorescein optics (right panels) to visualize GMF-beta $(A, C, E)$ or NGF receptor $(B, D, F)$. Control, uninjured nerve $(A$ and $B)$. $C$ and $E$, Endoneurial staining with G2-09 in the distal segment of sciatic nerve 1 week $(C)$ and 2 weeks $(E)$ after transection. Immunostaining of NGF receptor $(D, F)$ in sections adjacent to those of $C$ and $E$ shows an identical staining pattern to that obtained with G2-09. No staining with G2-09 $(A)$ or $192-\mathrm{IgG}(B)$ is detectable in sections of normal sciatic nerve. Scale bar, $50 \mu \mathrm{m}$.

ment of axonal contact results in the down-regulation of this protein.

The correlation of GMF-beta induction with axotomy may mean that GMF-beta plays a role in axonal repair. We propose that GMF-beta is one of several Schwann cell factors that pro- mote axonal regeneration (Taniuchi et al., 1988). Our recent observation that GMF-beta promotes neurite outgrowth from dorsal root ganglia in an in vitro assay (Lim and Miller, 1988) supports this contention. This is particularly relevant in view of the fact that dorsal root ganglia provide sensory fibers to the 

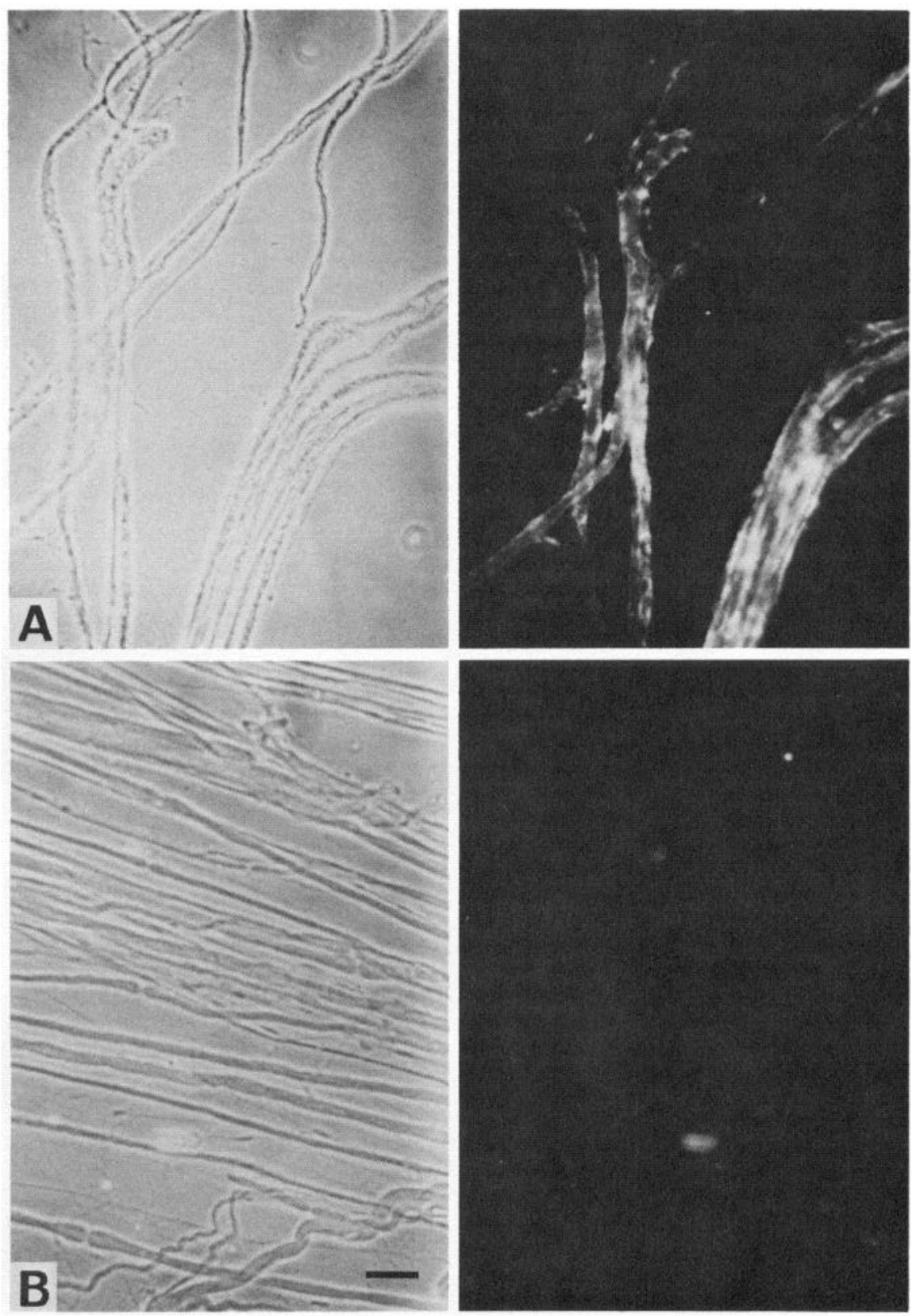

Figure 4. GMF-beta immunoreactivity in teased fiber preparations after crush injury. Phase contrast (left panels) and fluorescein optics (right panels) to visualize GMF-beta. $A$, Seven d and, $B$, 8 weeks postcrush injury of sciatic nerve. Note G2-09 positive staining of myelinated fibers $7 \mathrm{~d}$ after crush, whereas thinly myelinated fibers after regeneration $(B)$ are unstained. Scale bar, 50 $\mu \mathrm{m}$. spinal nerves. Alternatively, it is possible that GMF-beta may be an autocrine stimulator for Schwann cells (Lim et al., 1988a), affecting the axons indirectly by promoting the secretion of neuronal growth factors. The two possibilities are not mutually exclusive, although which one prevails deserves further consideration.

The influence of GMF on neurons is not limited to the peripheral nervous system. Using cruder preparations, we previously found that GMF promotes the recovery of brain tissue from injury inflicted in neonatal and adult rats (Lim and Miller, 1985; Lim et al., 1985b). In another experiment using behavioral monitoring, GMF-beta was found to reduce behavioral deficits after caudate nucleus injury in rats (Palatucci et al., 1988). Finally, an immunochemical study showed a selected, enhanced release of GMF-beta from the rat brain into a wound cavity created in the cerebral cortex (Nieto-Sampedro et al., 1988).

In the current study, immunolabeling for GMF-beta was car- ried out in parallel with immunostaining for NGF receptor, so that the changes in expression of these two molecules could be compared. It has been reported by other investigators that several proteins, including NGF, NGF receptor, and cell surface glycoproteins, are expressed by Schwann cells only in culture or following nerve injury and play a critical role in neuronal development and regeneration. In the adult nerve, the neural cell adhesion molecules N-CAM and $\mathrm{L}_{1}$ are restricted to nonmyelinforming Schwann cells (Mirsky and Jessen, 1986; Mirsky et al., 1986). In response to nerve transection or loss of axonal contact in culture, both neural cell adhesion molecules become reexpressed by the entire population of Schwann cells within days. During axonal regeneration, expression of both neural cell adhesion molecules ceases at the onset of myelination but continues on nonmyelin-forming Schwann cells and unmyelinated axons (Daniloff et al., 1986; Jessen et al., 1987). NGF is a protein produced by the target tissues of NGF-responsive neurons, i.e, 

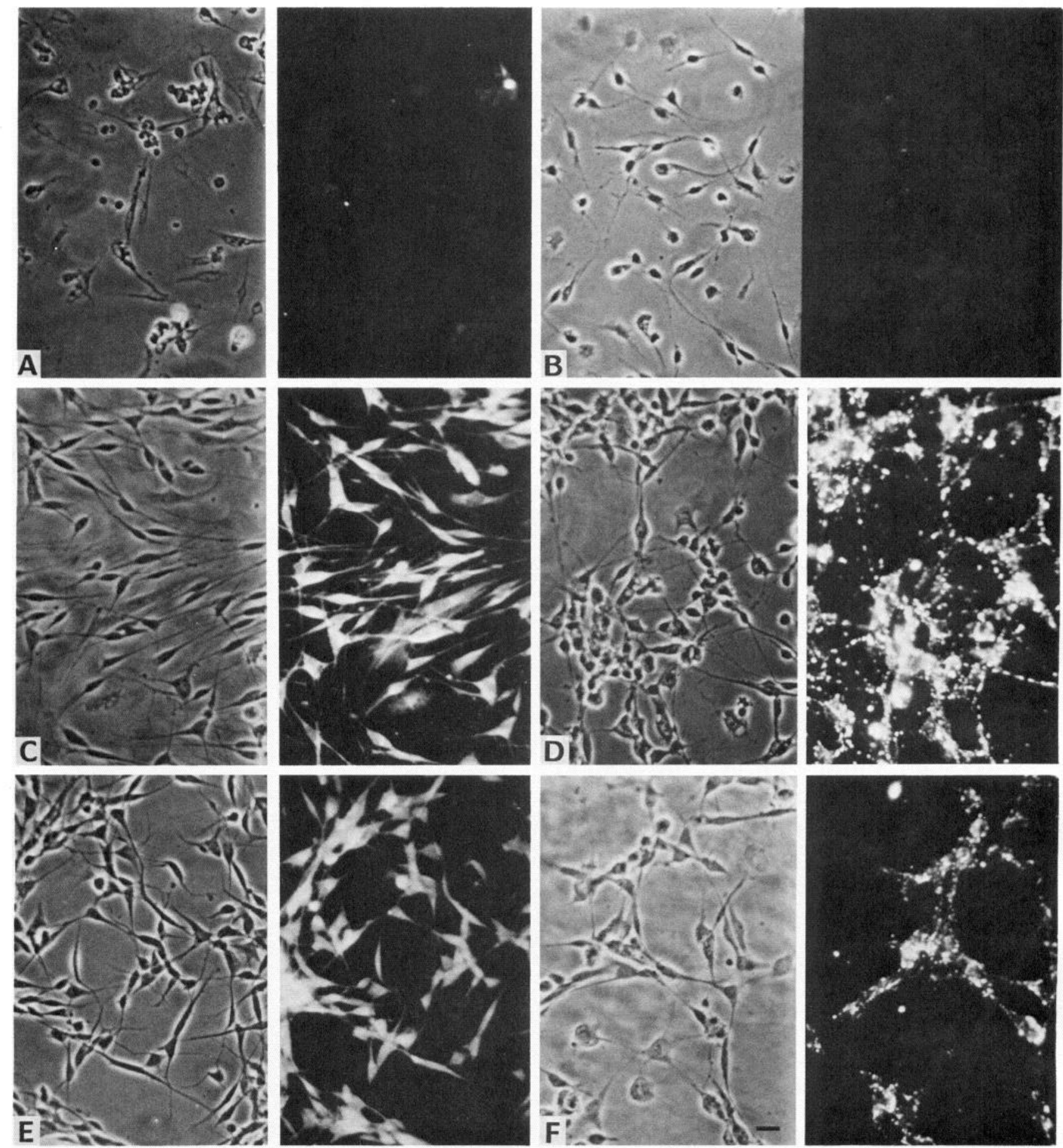

Figure 5. GMF-beta and NGF receptor immunoreactivity of newborn rat Schwann cell cultures. Phase contrast (left panels) and fluorescein optics (right panels) to visualize GMF-beta $(A, C, E)$ or NGF receptor $(B, D, F)$. C and $E$, Intracellular staining of all Schwann cells with G2-09 on $1 \mathrm{~d}$ $(C)$ and $7 \mathrm{~d}(E)$ cultures. Immunostaining of NGF receptor $(D, F)$ shows surface staining of all Schwann cells on $1 \mathrm{~d}(D)$ and $3 \mathrm{~d}(F)$ cultures. No definite staining with $\mathrm{G} 2-09(A)$ or 192-IgG $(B)$ is detectable $6 \mathrm{hr}$ after plating. Scale bar, $20 \mu \mathrm{m}$.

the neural crest-derived neurons, and acts as a retrograde neurotrophic messenger. In peripheral sympathetic and sensory neurons, the biological actions of NGF are initiated by binding of NGF to specific cell surface receptors (Thoenen and Barde, 1980). After nerve transection, Schwann cells and endoneurial fibroblasts distal to the lesion dramatically increase their syn- thesis of NGF (Heumann et al., 1987a). This is corroborated by the finding that Schwann cells in culture secrete an NGFlike neurite-promoting factor along with other less well characterized factors for NGF-independent neurons (Assouline et al., 1987; Bosch et al., 1988). Simultaneous with the enhanced synthesis of NGF, nerve transection leads to the induction of 

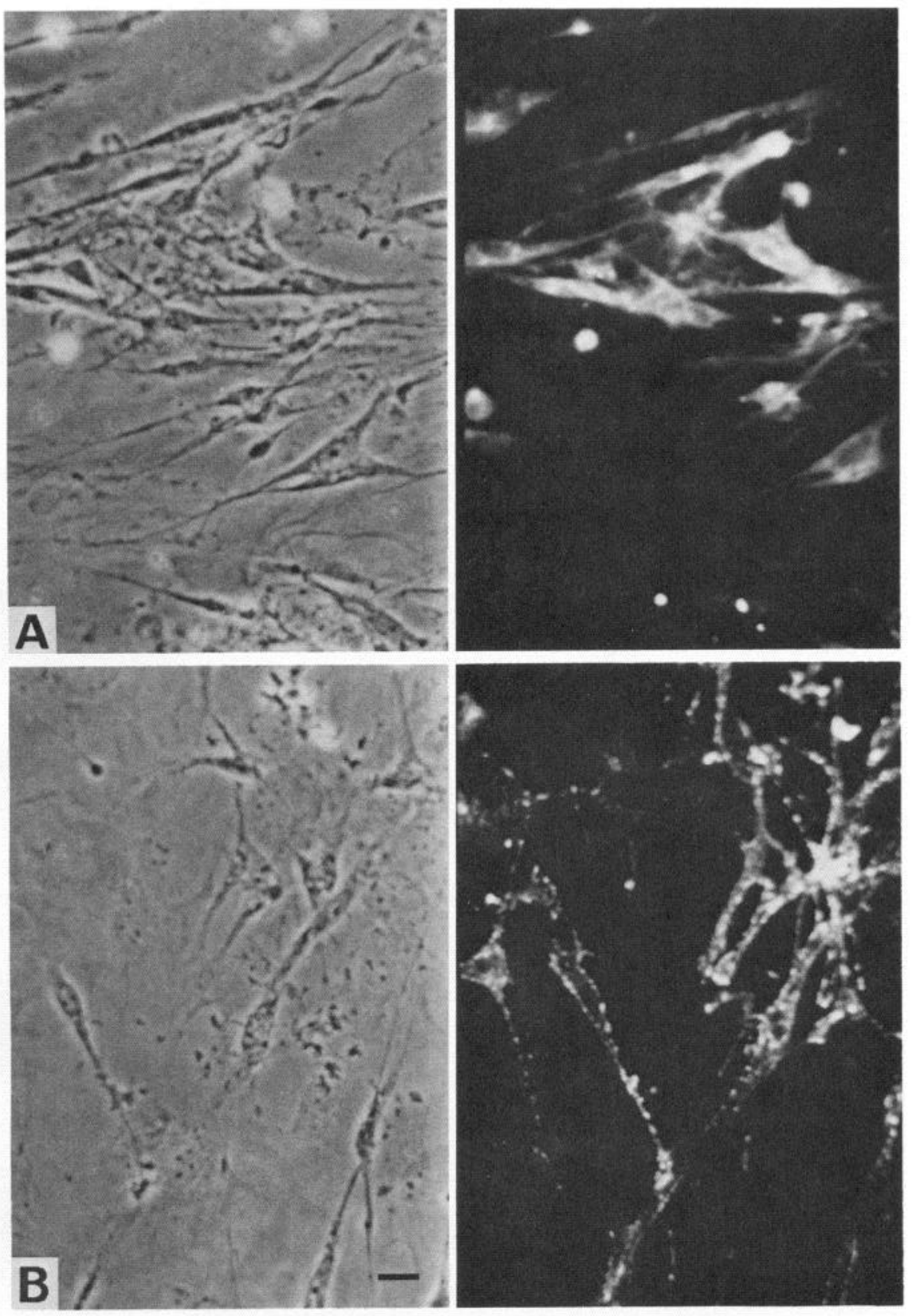

Figure 6. GMF-beta and NGF receptor immunoreactivity of adult human Schwann cell cultures. Phase contrast (left panels) and fluorescein optics (right panels) to visualize GMF-beta $(A)$ or NGF receptor $(B)$. All Schwann cells stain positively with $\mathrm{G} 2-09(A)$ and NGFR $5(B)$ on 6 d cultures. Fibroblasts are NGF receptor negative. Scale bar, $20 \mu \mathrm{m}$.
NGF receptors in the entire population of Schwann cells within the endoneurium distal to the lesion (Taniuchi et al., 1986; Heumann et al., 1987b; Raivich and Kreutzberg, 1987). The receptor density increases between 20 - and 50 -fold within 1 week, then declines, but remains elevated above control levels in the absence of axonal regeneration. Analogous to the experimental situation, increased NGF receptor immunoreactivity in human sural nerve biopsies has been found in peripheral neuropathies and correlated with the degree of axonal degeneration (Sobue et al., 1988). Reestablishment of axon-Schwann cell contact during regeneration down-regulates Schwann cell expression of the NGF-receptor (Taniuchi et al., 1988).

Recent studies have demonstrated that several nonneuronal cells derived from neural crest, including Schwann-like cells isolated from neurofibromas, and Schwann cells derived from chick, rat, and human nerves, express an NGF receptor in cul- ture (Zimmerman and Sutter, 1983; Pleasure et al., 1986; Yasuda et al., 1987; Scarpini et al., 1988). Characterization of the Schwann cell NGF receptor reveals that rat Schwann cells possess only low-affinity or class II receptors in contrast to highand low-affinity NGF binding sites on sympathetic and sensory neurons (Distefano and Johnson, 1988). The function of the low-affinity receptor is not clear because the biological activity of NGF is believed to be mediated via the high-affinity receptor. In fact, Schwann cells show no detectable biological responses to NGF except for its regulatory role in the expression of the neural cell adhesion molecule $\mathrm{L}_{1}$ (Seilheimer and Schachner, 1987).

Taniuchi and coworkers (1988) suggested the following possible functions for the Schwann cell NGF receptors. The simultaneous synthesis of NGF by endoneurial cells and the development of class II NGF receptors on Schwann cells during 
Wallerian degeneration may bind NGF along denervated Schwann cell columns to attract regenerating axonal sprouts of NGF-responsive neurons. Since the control of GMF-beta expression in Schwann cells by neuronal signals is strikingly similar to that of the NGF-receptor, it appears that GMF-beta could be one of several Schwann cell factors that promote axonal regeneration. Our understanding of the interaction of these agents will be an important step in dissecting the cellular and molecular mechanisms of peripheral nerve regeneration.

\section{References}

Assouline, J. G., E. P. Bosch, and R. Lim (1983) Purification of rat Schwann cells from cultures of peripheral nerve: An immunoselective method of using surfaces coated with anti-immunoglobulin antibodies. Brain Res. 277: 389-392.

Assouline, J. G., E. P. Bosch, R. Lim, S. Kim, R. Jensen, and N. J. Pantazis (1987) Rat astrocytes and Schwann cells in culture synthesize NGF-like neurite promoting factors. Dev: Brain Res. 31: 103118 .

Bosch, E. P., J. G. Assouline, J. F. Miller, and R. Lim (1984) Glia maturation factor promotes proliferation and morphologic expression of rat Schwann cells. Brain Res. 304: 311-319.

Bosch, E. P., J. G. Assouline, N. J. Pantazis, and R. Lim (1988) Schwann cell conditioned medium supports neurite outgrowth and survival of spinal cord neurons in culture. Muscle Nerve 11: 324-330.

Chandler, C. E., L. M. Parsons, M. Hosang, and E. M. Shooter (1984) A monoclonal antibody modulates the interaction of nerve growth factor with PC12 cells. J. Biol. Chem. 259: 6882-6889.

Daniloff J. K., G. Levi, M. Grumet, F. Rieger, and G. M. Edelman (1986) Altered expression of neuronal cell adhesion molecules induced by nerve injury and repair. J. Cell Biol. 103: 929-945.

Distefano, P. S., and E. M. Johnson, Jr. (1988) Nerve growth factor receptors on cultured rat Schwann cells. J. Neurosci. 8: 231-241.

Heumann, R., S. Korsching, C. Bandtlow, and H. Thoenen (1987a) Changes of nerve growth factor synthesis in non-neuronal cells in response to sciatic nerve transcction. J. Ccll Biol. 104: 1623-1631.

Heumann, R., D. Lindholm, C. Bandtlow, M. Meyer, M. J. Radeke, T. P. Miso, E. Shooter, and H. Thoenen (1987b) Differential regulation of mRNA encoding nerve growth factor and its receptor in rat sciatic nerve during development, degeneration and regeneration: Role of macrophages.' Proc. Natl. Acad. Sci. USA 84: 8735-8739.

Jessen, K. R., and R. Mirsky (1984) Nonmyelin-forming Schwann cells coexpress surface proteins and intermediate filaments not found in myelin-forming cells: A study of Ran-2, A5E3 antigen and glial fibrillary acidic protein. J. Neurocytol. 13: 923-934.

Jessen, K. R., R. Mirsky, and L. Morgan (1987) Myelinated, but not unmyelinated, axons reversibly down-regulate N-CAM in Schwann cells. J. Neurocytol. 16: 681-688.

Lim, R., and J. F. Miller (1985) Glia maturation factor influences recovery from injury in neonatal rat brains. Experientia 41: 412-415.

Lim, R., and J. F. Miller (1988) Isolation and sequence analysis of GMF-beta: A neural growth factor. J. Cell Biol. 107: 270a.

Lim, R., and K. Mitsunobu (1974) Brain cells in culture: Morphological transformation by a protein. Science 185: 63-66.

Lim, R., W. K. P Li, and K. Mitsunobu (1972) Morphological transformation of dissociated embryonic brain cells in the presence of brain extracts. Abstracts, 2nd Meeting, Soc. Neurosci., Houston, Texas, p. 181.

Lim, R., K. Mitsunobu, and W. K. P. Li (1973), Maturation-stimulating effect of brain extract and dibutyryl cyclic AMP on dissociated embryonic brain cells in culture. Exp. Cell Res. 79: 243-246.

Lim, R., D. E. Turriff, and S. S. Troy (1976) Response of glioblasts to a morphological transforming factor from adult brain: Cinematographic and chemical correlations. Brain Res. 113: 165-170.

Lim, R., S. S. Troy, and D. E. Turriff (1977a) Fine structure of cultured glioblasts before and after morphological transformation by a maturation factor. Exp. Cell Res. 106: 357-372.

Lim, R., D. E. Turriff, S. S. Troy, B. W. Moore, and L. F. Eng (1977b) Glia maturation factor: Effect on chemical differentiation of glioblasts in culture. Science 195: 195-196.
Lim, R., J. F. Miller, D. J. Hicklin, and A. A. Andresen (1985a) Purification of bovine glia maturation factor and characterization with monoclonal antibody. Biochemistry 24: 8070-8074.

Lim, R., J. F. Miller, and G. Toffano (1985b) Glia maturation factor promotes nigro-striatal regeneration. Trans. Am. Soc. Neurochem. 16: 307 .

Lim, R., D. J. Hicklin, T. C. Ryken, and J. F. Miller (1987a) Endogenous immunoreactive glia maturation factor-like molecule in astrocytes and glioma cells. Dev. Brain Res. 33: 49-57.

Lim, R., D. J. Hicklin, J. F. Miller, T. H. Williams, and J. B. Crabtree (1987b) Distribution of immunoreactive glia maturation factor-like molecule in organs and tissues. Dev. Brain Res. 33: 93-100.

Lim, R., D. J. Hicklin, T. C. Ryken, J. F. Miller, and E. P. Bosch (1988a) Endogenous immunoreactive glia maturation factor-like molecule in cultured rat Schwann cells. Dev. Brain Res. 40: 277-284.

Lim, R., W. Zhong, E. P. Bosch, and J. F. Miller (1988b) Expression of GMF-like protein after scialic nerve transection. Trans. Am. Soc. Neurochem. 19: 83 .

Lim, R., J. F. Miller, and A. Zaheer (1989) Purification and characterization of glia maturation factor-beta: A growth regulator for neurons and glia. Proc. Natl. Acad. Sci. USA 86: 3901-3905.

Marano, N., B. Dietzschold, J. J. Earley, Jr., G. Schatteman, S. Thompson, P. Carob, A. H. Ross, M. Bothwell, B. Atkinson, and H. Koprowski (1987) Purification and amino terminal sequencing of human melanoma nerve growth factor receptor. J. Neurochem. 48:225232.

Mirsky, R., and K. R. Jessen (1986) The biology of non-myelin-forming Schwann cells. Ann. NY Acad. Sci. 486: 132-146.

Mirsky, R., K. R. Jessen, M. Schachner, and C. Goridis (1986) Distribution of the adhesion molecules N-CAM and $\mathrm{L}_{1}$ on peripheral neurons and glia in adult rats. J. Neurocytol. 15: 799-815.

Nieto-Sampedro, M., R. Lim, D. J. Hicklin, and C. W. Cotman (1988) Early release of glia maturation factor and acidic fibroblast growth factor after rat brain injury. Neurosci. Lett. 86: 361-365.

Palatucci, C. M., D. Charbonnier, R. Lim, and D. G. Stein (1988) Glia maturation factor reduces behavioral deficits after caudate nucleus injury in rats. Soc. Neurosci. Abstr. 14: 584.

Pleasure, D., B. Kreider, G. Sobue, A. M. Ross, H. Koprowski, K. H. Sonnenfeld, and A. E. Rubenstein (1986) Schwann-like cells cultured from human dermal neurofibromas: Immunohistological identification and response to Schwann cell mitogens. Ann. NY Acad. Sci. 486: $227-240$.

Raivich, G., and G. W. Kreutzberg (1987) Expression of growth factor receptors in injured nervous tissue. I. Axotomy leads to a shift in the cellular distribution of specific $\beta$-nerve growth factor binding in the injured and regenerating PNS. J. Neurocytol. 16: 689-700.

Scarpini, E., A. H. Ross, J. L. Rosen, M. J. Brown, A. Rostami, H. Koprowski, and R.P. Lisak (1988) Expression of nerve growth factor receptor during human peripheral nerve development. Dev. Biol. 125: 301-310.

Seilheimer, B., and M. Schachner (1987) Regulation of neural cell adhesion -molecule expression on cultured mouse Schwann cells by nerve growth factor. EMBO J. 6: 1611-1616.

Sobue, G., T. Yasuda, T. Mitsuma, A. H. Ross, and D. Pleasure (1988) Expression of nerve growth factor receptor in human peripheral neuropathies. Ann. Neurol. 24: 64-72.

Taniuchi, M., H. B. Clark, and E. M. Johnson, Jr. (1986) Induction of nerve growth factor receptor in Schwann cells after axotomy. Proc. Natl. Ácad. Sci. USA 83: 4094-4098.

Taniuchi, M., H. B. Clark, J. B. Schweitzer, and E. M. Johnson, Jr. (1988) Expression of nerve growth factor receptors by Schwann cells of axotomized peripheral nerves: Ultrastructural localization, suppression by axonal contact, and binding properties. J. Neurosci. 8: $664-681$.

Thoenen, H., and Y. A. Barde (1980) Physiology of nerve growth factor. Physiol. Rev. 4: 1284-1332.

Yasuda, T., G. Sobue, K. Mokuno, N. Kreider, and D. Pleasure (1987) Cultured rat Schwann cells express low affinity receptors for nerve growth factor. Brain Res. 436: 113-119.

Zimmermann, A., and A. Sutter (1983) $\beta$-NGF receptors on glial cells. Cell-cell interaction between neurones and Schwann cells in cultures of chick sensory ganglia. EMBO J. 2: 879-885. 